\title{
CELESTINESCA
}

https://doi.org/10.7203/Celestinesca.12.19672

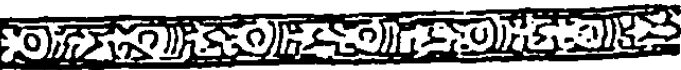

\section{UNA NUEVA TRAGICOMEdiA CELESTINESCA DEL SIGLO XVI}

\author{
Stefano Arata \\ Universidad de Roma
}

Según una clasificación hoy generalmente aceptada por la critica, podemos dividir las piezas literarias de los siglos XVI y XVII que se inspiran en la Tragicomedia de Fernando de Rojas en dos grupos bien diferenciados. Por un lado, tenemos el género de la celestinesca, que se desarrolla en España entre 1521 y 1554 , y que abarca un conjunto de siete obras: La comedia Thebaida, La segunda comedia de Celestina, La tercera parte de la tragicomedia de Celestina, La tragicomedia de Lisandro y Roselia, La tragedia Policiana, La comedia llamada Florinea y La comedia Selvagia. Por otro, el ámbito más indefinido de lo celestinesco, que incluye, en general, obras más tardias como La Lena de Velázquez de Velasco o La Dorotea de Lope de Vega. ${ }^{1}$ Las piezas del primer grupo se caracterizan no sólo por reproducir el juego de amor, inscrito en un triángulo amoroso entre los nobles amantes y la intermediaria con su camarilla de hijas y rufianes, sino por proponerse como continuaciones directas de la Celestina primitiva, en oposición a las piezas del ámbito celestinesco, que se limitan a desarrollar aspectos parciales del modelo.

La reducida familia de la celesinesca se puede ver ampliada, ahora, por el hallazgo de un octavo ejemplar: una pieza manuscrita del siglo XVI que he tenido la ocasion de encontrar en la Biblioteca del Palacio Real de Madrid.

Los investigadores que han tratado de forma más pormenorizada la tradición celestinesca (Menéndez Pelayo, Lida de Malkiel, Bataillon, Hillard, Heugas) ${ }^{2}$ no mencionan en sus estudios este manuscrito. Tampoco he podido encontrarlo citado en los repertorios bibliográficos sobre la celestinesca $\mathrm{ni}$ en los repertorios generales de la literatura del siglo XVI. Parece tratarse, pues, de una obra inédita $y$, al parecer, completamente desconocida, de la cual voy a dar breve noticia en las páginas siguientes.

La pieza se conserva en un manuscrito que lleva la signatura II1591 (olim 2-B-10), en tamaño de pequeño $4^{2}$ (mm $200 \times 145$ ), compuesto por ff. $\mathrm{I}+109+\mathrm{I}$, sin numerar. El texto, que ha sido redactado 


\section{CELESTINESCA}

por una sola mano y dispuesto sobre 21 renglones por página, presenta escasas enmiendas y tachaduras. La letra humanistica, muy caligráfica y de fácil lectura, nos remite a la segunda mitad del siglo XVI. Difícil es determinar si se trata de un manuscrito autógrafo o de una copia llevada a cabo por algún copista, aunque la falta casi completa de errores de transcripción y la naturaleza de algunas enmiendas parecen abogar por la primera hipótesis. La encuadernación actual es del siglo XVIII, en pasta, con hierros dorados en la portada y lomo cuajado. En el tejuelo marrón, en letras de oro, dice: "POLIDOR [sic]/ COMEDIA."

Por la probable pérdida del primer folio del manuscrito, o quizá de una antigua portadilla, la obra carece de título y del nombre del autor, comenzando directamente con unos tercetos del "autor a los lectores escusándose de haber publicado la obra." Desafortunadamente, los versos no son acrósticos $y$, por otra parte, el autor no nos of rece datos que nos permitan identificarlo o adelantar alguna hipótesis sobre su persona. El título, "Polidor[o] Comedia," que leemos en el tejuelo de la encuadernación dieciochesca, es verosimilmente postizo: en ningún momento el manuscrito habla de "comedia" ni hace referencia al nombre de Polidoro como título. Con el fin de evitar posibles confusiones homonimicas con la comedia humanistica Poliodorus, ${ }^{3}$ que nada tiene que ver con la pieza de Palacio, y ciñendome, por otra parte, a la tradición de los titulos celestinescos, denominaré esta obra, de forma provisional, Tragicomedia de Polidoro $y$ Casandrina, titulo que recoge los nombres de los dos amantes de la pieza.

La obra, precedida por un prólogo recitado por el personaje de la Fortuna, se divide en tres actos de cinco escenas cada uno. Transcribo, a continuación, los argumentos de cada escena, que resumen de forma detallada la intriga de la tragicomedia.

I.1. Polidoro, soberbio con la gran riqueza, se da a entender que la Fortuna está dél enamorada y que las tres Parcas, que hilan la vida, están sugetas a su seruicio, y loándose desto, hurtan dél sus criados, diziéndole algunos donaires, los quales él, con su ciega locura, no entiende.

I.2. Gabaldo, ayo de Polidoro, doliéndose de las locuras y liuiandades y uanas ymaginaciones de Polidoro, le da a entender con aprobaciones como la Fortuna no es diosa, y como de todos es engañado, el qual Polidoro burla de todo quanto su ayo dize.

1.3. Llama Polidoro sus criados para murmurar de Gabaldo, su ayo, lo qual hazen de buena gana. Traen a Polidoro grandes rriquezas de Yndias, las quales embia a buscar con Gabaldo por echarle de si, y queda Salustico solo con Polidoro, loando su astucia en ser lisongero.

I.4. Aconseja Gabaldo a Polidoro como ha de usar de las rriquezas que le han traido, y disputan largo él i Polidoro contra Tristán y Salustico, 


\section{CELESTINESCA}

sobre las uanas prosperidades desta uida. Pruéuales Gabaldo que es imposible consistir la felicidad en cosas deste mundo.

I.5. .. Salustico, auiendo rreçebido un golpe de dinero de su amo, sale diziendo mill bienes del oro, y Tristán y Rufino, de embidia, dizen mal dél a su amo, y su amo no los cree. Uase Salustico a guardar su dinero, y quedan Tristán y Rufino aconsejando mal a su amo, el qual, creyéndoles, les fia el arca de los dineros, y ellos, en pago desto, conciertan rreboluerle con una muger hermosa, hija de una muy gran hechizera.

II.6. Salustico, que uiene de guardar su moneda, se topa con Polidoro, su amor, que uiene del campo, enamorado de una dama que se topó en el camino. Entiende Salustico ser aquel enamoramyento obra de sus contrarios, Tristán y Rufino, y trata de apartar a Polidoro de las cosas del amor, y de las mugeres.

II.7. Casandrina, cantonera, hija de la Corneja, hechizera, saliendo al campo uyó a Polidoro en la rribera del rrio, y enamorada dél, lo descubre a su madre, diziendo que le quiere yr a buscar. La madre la rreprehende, y dexándola cerrada en casa, se ua a buscar a Tristán para tratar con ellos amores de Polidoro con Casandrina su hija, y en el camino se topa con Salustico, y conócense, y dizele que ua a buscar dineros prestados para casar a su hija, y Salustico se los offrece a buscar, y con esto se despiden.

II.8. Vestidos Tristán y Rufino, se topan con la Corneja y descúbrenle su intención, y ella se huelga con la buena nueua, y ellos se tornan a Polidoro, y ella se fue a su casa, adonde ynuoca sus familiares por estraña manera, y luego se ua en casa de Polidoro.

II.9. Llegados Tristán y Rufino en casa de Polidoro, danle qüenta de como an uisto una dama, y él no muestra mucho rrostro a lo que le dizen. Uan a buscar a la Corneja, la rremediadora, y hállanla en una tauerna. Uanse todos tres en casa de Polidoro, y la uieja le da los hechizos por engaño y uase. Polidoro se torna loco. Diçe la Corneja a los demonios que no sean tan diligentes sino que le tiemplen el furor. Embáucanle sus criados y enamórase, y para yr a la noche a uer a Casandrina, embia una solene cena y doseles para que aderezen la casa.

II.10. Venida la noche, queda Polidoro en casa de la Corneja, y Salustico traba amistad con Tristán y Rufino, y ellos fingen que la acetan, y dexan a Polidoro con Casandrina, y uan a Salustico, y porque no le da los dineros que le a dado su amo, le matan, y, muerto, se uan a saquear la casa de su amo, y Polidoro, descontento de su amiga, como es hordinario, se ua a buscar a sus criados. La Corneja, como astuta, se alça con la ganançia, y se ua a biuyr con su hija a la ciudad de Toledo. 
III.11. Las tres Parcas, a rruego de la Fortuna, su amiga, hilan la uida de Polidoro con toda presteza, y hilándola, disputan entre si mesmas la miseria desta humana uida.

11I.12. Polidoro se quexa de la Fortuna porque tan mal le comiença a tratar, que se le han leuantado los hazederos que tenia en Yndias, y se le anegaron las naos en que le uenian gran suma de dineros. Uéese con poco de lo mucho que solia tener. Uende los bienes que le quedan y con ellos se quiere pasar en las Yndias. Tratan los criados de rrobarle el dinero que hiziere de las cosas que quiere uender.

III.13. Uiene el mercader, [Tristán y Rufino] tómanle por engaño los dineros, y después rroban los uestidos a Polidoro que está durmiendo, y uanse a guardar su dinero con determinación de uenir y matar a Polidoro.

III.14. Viéndose Polidoro tan cercado de trabajos, quéxase, y llama a la Fortuna que le rresponda diziendo que por qué ha dado la buelta tan a su daño. La Fortuna rresponde largamente, diziéndole su parecer.

III.15. Matan los criados a Polidoro, y sobre el partir de los dineros, se matan entrambos. Llega Gabaldo y concluye la obra con una lamentación que haze sobre la muerte de Polidoro.

Para fechar la Tragicomedia de una forma aproximada, además de las consideraciones paleográficas, que apuntan hacia la segunda mitad del siglo XVI, encontramos en el texto una alusión a un hecho contemporáneo que nos proporciona el término post quem de la redacción de la obra. En la quinta escena del primer acto, el criado Salustico, alabando su propria inteligencia, recuerda que "más vale un sabio que veinte necios. Con menos de diez mill hombres uenció Leónidas al inumerable exército de Xerxes, y agora, en nuestros tiempos, ¿no ganó a Affrica, cabeça de toda Berberia, don Garçia de Toledo, con seis mill hombres?" Salustico se refiere aqui, con toda seguridad, a la conquista del Peñón de Gomera, en Marruecos, llevada a cabo en 1564 por Garcia de Toledo, marqués de Villafranca. La hazaña, que permitió eliminar un punto de máximo peligro para el tráfico comercial en la zona, valió a Garcia de Toledo como recompensa el nombramiento de virrey de Sicilia. Otras dos alusiones a acontecimientos politicos, que encontramos en el texto--una mención genérica a "nuestro rrey don Felipe" y una a la época en que la Corte estaba en Valladolid--no nos permiten aproximarnos ulteriormente a la fecha de composición de la Tragicomedia, fecha que tenemos que fijar, de forma provisional, en los años siguientes a la toma del Peñon de Gomera, cuando los lectores podian apreciar en todo su valor la alusión a la hazaña del marqués de Villafranca. 


\section{CELESTINESCA}

No es éste el lugar adecuado para esbozar un análisis, siquiera somero, de los aspectos temáticos y estilisticos de la obra, para lo cual remito a la edición que estoy actualmente preparando de la Tragicomedia de Polidoro y Casandrina.

Antes de terminar esta breve nota, sin embargo, quisiera mencionar la interesante relación que establece el anónimo autor entre algunos de sus personajes y los protagonistas celestinescos, en particular entre Corneja y Celestina.

Como explica Rufino a Tristán en la quinta escena del primer acto:

Ella [Corneja] es natural de Salamanca, en donde, en tiempo de los Reyes Católicos, se leýa nicromancia y diabólica facultad, la qual, por los bien auenturados Reyes fue desterrada, mas no pudo erradicar que como simiente no dexase rrastro de si por muchas partes, principalmente en libianas mugeres, puesto caso que el método quedó en la antigua Claudina, que Dios aya. A ésta suscedió la famosa Celestina, que como yngeniosa, dio tal qüenta de si en el officio, que tuuiera Claudina más rrazón de matalla que tuuo Hipócrates de matar a Galeno. Tras ésta fue Elicia, que dizen que es madre de Salustico, que no degeneró a sus antecesoras, que dexando el luto, se dio tal maña que dexó tal memoria de sí, que la lloraron estudiantes y moços d'espuelas, y las del colegio de la cadenilla echaron menos sus documentos. Y en la escuela desta aprendió la Corneja, que aora biue, no menos sabia que las pasadas, porque ha mostrado gran abilidad entre todas sus coetáneas...

La relación de Rufino, aparte de confirmar la leyenda salmantina sobre Celestina--que como sabemos tuvo cierta vigencia en el siglo XVI-recoge la génealogia de la hechiceria que se habia ido forjando con la Tragicomedia de Rojas y con algunas de las continuaciones, proponiendo a Corneja cual descendiente directa de la rama Claudina-Celestina-Elicia. El parentesco con la gran familia celestinesca queda además cimentado-y casi diria autorizado--por la relación sanguinea que une a Salustico y Elicia, y que reproduce, no lo olvidemos, la relación madre-hijo existente entre Claudina y Pármeno en la primitiva Celestina.

La Tragicomedia de Polidoro y Casandrina, por tanto, al tiempo que nos descubre las andanzas de una desconocida descendiente de Celestina, nos permite añadir un ulterior eslabón al ciclo de la celestinesca, alargando el ámbito temporal del género hasta bien entrado el reinado de Felipe II. 


\section{CELESTINESCA}

\section{NOTAS}

${ }^{1} \mathrm{P}$. Heugas, La Célestine et sa descendence directe, Bordeaux 1973.

${ }^{2}$ M. Menéndez Pelayo, Origenes de la novela, III; (NBAE, 14), Madrid 1910; M. R. Lida de Malkiel, La originalidad artistica de La Celestina, Buenos Aires 1962; M. Bataillon, La Célestine selon Fernando de Rojas, Paris 1961; E. Hillard, Spanish Imitations of La Celestina, Diss. Univ. of Illinois, 1957; P. Heugas, op.cit.

$3_{\mathrm{J}}$. de Vallata, "Poliodorus": Comedia humanistica desconocida, ed. J. M. Casas Homs, Madrid: CSIC, 1953.

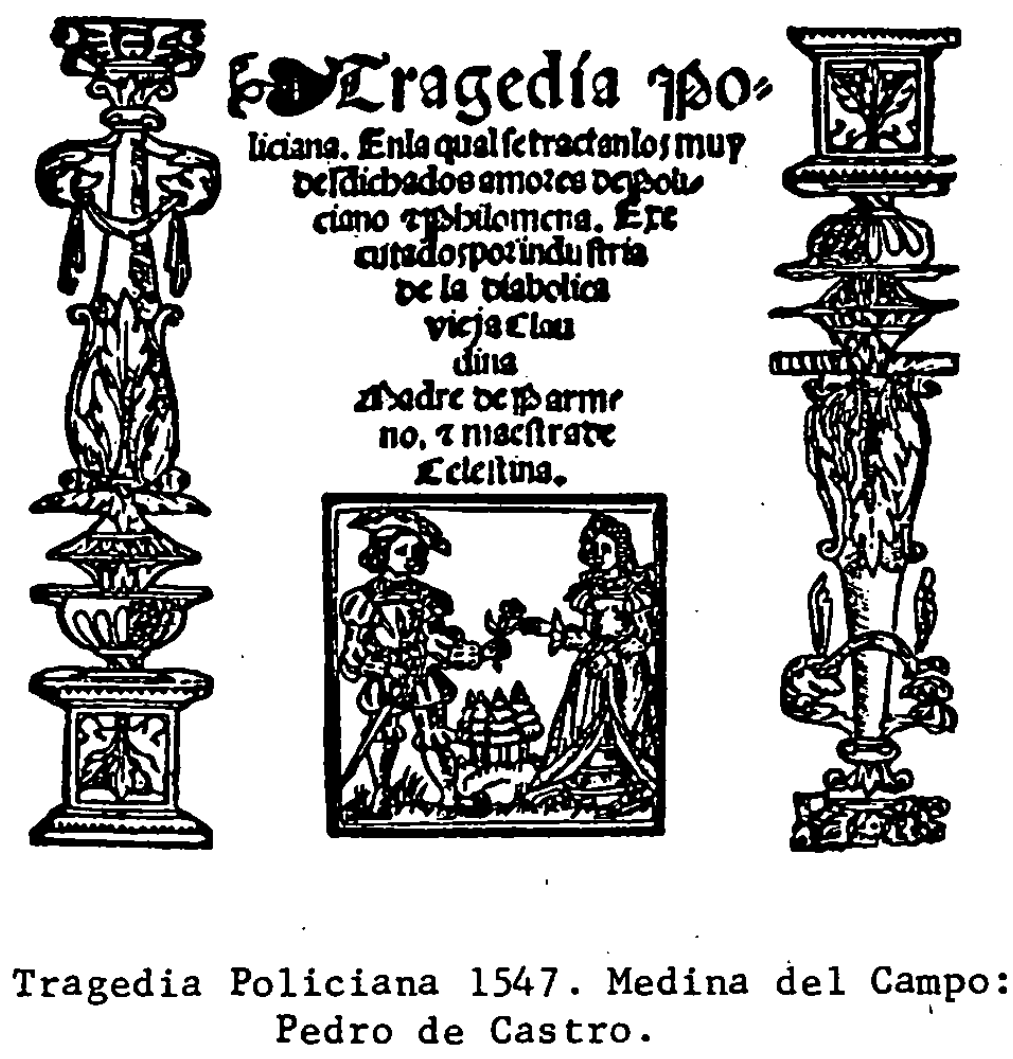

